\title{
THE
}

\section{High Pressure and High Magnetic Field Effects on Spin-Peierls Systems}

D. Bloch

J. Voiron

C. Vettier

J. Kommandeur

J. W. Bray

See next page for additional authors

Follow this and additional works at: https://digitalcommons.uri.edu/phys_facpubs

Terms of Use

All rights reserved under copyright.

\section{Citation/Publisher Attribution}

Bloch, D., Voiron, J., Vettier, C., Kommandeur, J., Bray, J. W., Jacobs, I. S.,...Bonner, J. C. (1982). High Pressure and High Magnetic Field Effects on Spin-Peierls Systems. Physica Scripta, 1982, 24. doi: 10.1088/0031-8949/1982/T1/008

Available at: http://dx.doi.org/10.1088/0031-8949/1982/T1/008

This Article is brought to you for free and open access by the Physics at DigitalCommons@URI. It has been accepted for inclusion in Physics Faculty Publications by an authorized administrator of DigitalCommons@URI. For more information, please contact digitalcommons-group@uri.edu. 


\section{Authors}

D. Bloch, J. Voiron, C. Vettier, J. Kommandeur, J. W. Bray, I. S. Jacobs, L. V. Interrante, and Jill C. Bonner 


\section{Related content}

\section{High Pressure and High Magnetic Field Effects on Spin-Peierls Systems}

To cite this article: D Bloch et al 1982 Phys. Scr. 198224

- Surface Field Effect on the Breakdown of
Ge Grain Boundary
Hiroshi Edagawa, Tsutomu Shibaike,
Yoshinori Morita et al.
- $\frac{\text { High Magnetic Field Effect on Exciton }}{\text { Energies in CdTe/Cd }}+\mathrm{Mn}_{\star}$ Te Quantum
$\frac{\text { Wells Grown by MBE }}{\text { Shinji Kuroda, Yutaka Shirai, Kazutoshi }}$
Kojima et al.
-
$\frac{\text { High Field Effects above the Gunn }}{\text { Threshold in n-Type GaAs }}$
Akiyasu Yamashita

View the article online for updates and enhancements.

Akiyasu Yamashita 


\title{
High Pressure and High Magnetic Field Effects on Spin-Peierls Systems
}

\author{
D. Bloch and J. Voiron \\ Laboratoire Louis Néel, CNRS, 166X, 38042 Grenoble Cédex, France \\ C. Vettier \\ Institut Laue-Langevin, 156X, 38042 Grenoble Cédex, France \\ J. Kommandeur \\ Laboratory for Physical Chemistry, University of Gröningen, Gröningen, The Netherlands \\ J. W. Bray, I. S. Jacobs and L. V. Interrante \\ General Electric Corporate, Res. \& Dev. Center, Schenectady, N.Y. 12301, U.S.A. \\ J. C. Bonner \\ Phy sics Department, University of Rhode-Island, Kingston, R.I., N.Y. 02881, U.S.A.
}

Long range magnetic orders do not take place at finite temperature in ideal one-dimensional magnetic systems. In the last decades a large number of quasi-one-dimensional compounds have been prepared. At sufficiently high temperatures they behave as predicted for really one-dimensional systems. However, at low temperatures, a cross-over takes place to a state of higher dimensionality. We will examine $S=1 / 2$ antiferromagnetic Heisenberg chain. They present, at low temperatures an antiferromagnetic Néel state or a spin-Peierls state [1].

High magnetic fields and high pressure experiments, where magnetization, neutron scattering, transport properties have been studied at high magnetic fields or high hydrostatic pressure are reported. Non-magnetic to magnetic transitions are obtained as a function of both applied magnetic field and hydrostatic pressure. These experiments have been performed on two donnor-acceptor compounds, TTF-BDT $(\mathrm{Cu})$ and MEM (TCNQ) $)_{2}$ which present spin-Peierls transitions respectively at $12 \mathrm{~K}[2,3]$ and at $19 \mathrm{~K}[4,5]$. MEM(TCNQ) $)_{2}$ is of major interest since it possesses also an electronic Peierls transition at $T=335 \mathrm{~K}$ and atmospheric pressure. Then in $\operatorname{MEM}(\mathrm{TCNQ})_{2}$, the spin-Peierls transition, $T_{\mathrm{SP}}$, which is a magnetic to non-magnetic transition is associated with a $2 k_{\mathrm{F}}$ lattice distortion and the electronic Peierls transition $T_{\mathrm{EP}}$, which is a metal to insulator transition, is associated with a $4 k_{\mathrm{F}}$ lattice distortion.

In the two compounds, it has been shown that the $T_{\mathrm{SP}}$ transition decreases with the applied field. Below $T_{\mathrm{SP}}$, it appears in high field a new magnetic phase, characterized by a susceptibility which does not decrease to zero with the temperature. The critical fields are respectively $110 \mathrm{kOe}$ and $190 \mathrm{kOe}$ for TTF-BDT $(\mathrm{Cu})$ and MEM(TCNQ $)_{2}[6,7]$.

In MEM(TCNQ) $)_{2}$ the high pressure phase diagram evidences a rapid decrease of the electronic Peierls transition [8] and an increase of the spin-Peierls transition with the applied pressure [9]. Above $4 \mathrm{kbar}$, the $2 k_{\mathrm{F}}$ and the $4 k_{\mathrm{F}}$ distortions disappear. The crystallographic parameters of the triclinic cell have been determined at $4.2 \mathrm{kbar}$ and high pressure (4.6 kbar). These parameters are very close to those measured in the uniform phase above the electronic Peierls transition [9].

\section{References}

1. For a review see: Bray, J. W., Interrante, L. V., Jacobs, I. S. and Bonner, J. C., in Extended Linear Chain Materials (Edited by J. S. Miller). Plenum, New York (1982); de Jongh, L. J. and Miedema, A. R., Adv. Phys. 23, 1 (1974).

2. Bray, J. W. et al., Phys. Rev. Letters 35, 744 (1975).

3. Jacobs, I. S. et al., Phys. Rev. B14, 3036 (1976).

4. Huizinga, S. et al., Phys. Rev. B19, 4723 (1979).

5. Huizinga, S., Thesis, Gröningen (1980).

6. Bloch, D. et al., Phys. Rev. Letters 44, 294 (1980).

7. Bloch, D. et al., Phys. Letters 82A, 21 (1981).

8. Bloch, D. et al., in Physics of Solids Under Pressure. (Edited by J. S. Schilling and R. N. Shelton). North Holland, Amsterdam (1981).

9. Bloch, D. et al., To be published. 